\title{
Creating actionable knowledge for sustainability: a case of "standards in the making"
}

\author{
Allison Loconto and Marc Barbier \\ INRA, UR1326 Sciences en Société, F-77420 Champs-sur-Marne, France \\ Institute for Research Innovation and Society (IFRIS) \\ Université Paris-Est Marne-la-Vallée, 5 blvd. Descartes, F77420 Champs-sur-Marne, France
}

\begin{abstract}
Social and environmental standards development organizations (SDOs) have been collaborating together to construct 'meta-standards'. These exercises in standards-setting are part of a longer-term process of transitioning innovative approaches to sustainable agriculture from diverse niches such as organic, fair trade and environmental conservation into a regime of certified sustainability. Using participant observation during the development of an Assurance Code, we examine how actors construct the tools that enable them to influence the broader transition to sustainability. We do this by focusing on intermediation activities by 'experts' during the development of a 'meta-standard' for assurance. The purpose of this chapter is twofold. First, we propose that in order to understand transitions in progress, we should be attentive to how these processes are accompanied by intermediation activities. Second, we argue that intermediate objects (or boundary objects) are important in these processes as they help actors to create actionable knowledge. These intermediation activities and the production of actionable knowledge contribute to the ability of actors to govern markets in the transition towards sustainable agriculture.
\end{abstract}

Keywords: certification; intermediation; sustainability; standards; transitions

Suggested Citation: Loconto, A., \& Barbier, M. (forthcoming 2017) "Creating actionable knowledge for sustainability: A case of 'standards in the making'." In V. Higgins, Miele, M.,Bjorkhaug, H., \& Koc, M. eds. The new challenges for the rural. Bingley, UK, Emerald Group Publishing Limited. 


\section{Introduction}

Since the 1987 Brundtland Report, public discourse characterizes sustainability as a positive vision for the future based on an alleged equilibrium between social equity, environmental conservation, and economic wealth. This triggered the development of socio-technical imaginaries that both organize and perform a vision of the future (e.g., Jasanoff and Kim 2009). But, sustainability is also a 'wicked problem' (Batie 2008; Levin et al. 2012). More than an ill-structured problem for decision-making, sustainability entails a political and inter-organizational dimension of a 'complex socio-biological technological problem' that is difficult to define, to localize and to attribute responsibility to specific actors. This is because it is interdependent on other related problems and continuously managed rather than necessarily solved (Batie 2008). Non-Governmental Organizations (NGOs) have played a pioneering role in whistle-blowing and in experimenting with new pathways of sustainability. One such pathway is through the use of sustainability standards. This is a global social process that is becoming increasingly important in rural transformations around the world, which is the focus of this edited collection.

The term 'sustainability standard' is used by the international community to refer to voluntary standards that contain social, environmental and economic criteria (UNFSS 2012). Sustainability Standards (SSs) provide a vision of sustainability based on the management of socio-economic and environmental processes (Loconto and Fouilleux 2014; Mutersbaugh 2005) and a way to guide this change through the multiple layers of audit found in conformity assessment systems (Hatanaka, Konefal and Constance 2012; Loconto and Busch 2010). Sustainability Standards Development Organizations (SDOs) propose that SSs are one means to manage sustainability strategically. Over the past 10 years, a variety of SDOs have banded together in what they call a 'sustainability standards movement'. Through this effort these SDOs are building a cognitive and practical alliance between producers, retailers and consumers. This is accompanied by a road map of the types of practical and scientific knowledge needed to guide them. Currently, the main organizing agent in this movement is the ISEAL Alliance (International Social and Environmental Accreditation and Labelling Alliance), which was officially created in 2002. In order to put into place such a roadmap, there must be a transition from what one does now, to what one will do in the future. The notion of a socio-technical imaginary borrowed from Jasanoff and Kim (2009) is particularly suited in this case as it describes a set of collectively imagined forms of social life and social order that are reflected in the design and fulfillment of international scientific and/or technological projects. A socio-technical imaginary explains that these forward-looking visions are guided by a type of 'knowing in action' based on differences found in creative purposes and in epistemic spaces (Amin and Roberts 2008). However, this process is not as much steered as it is a process of accommodating existing practices in international arenas of sustainability governance. NGOs and various intermediary organizations develop opportunistic action within on-going innovation dynamics and try to catalyse smaller changes with the expectation of broader effects. Such a transition to sustainability is a process of accompanied change where different types of actors mediate and modulate the visions, institutions and innovations of others (Jørgensen 2012). This means that an examination of this transition in progress must focus on "learning and experimentation with a variety of innovations in a variety of projects which are to link up with institutional changes" (Elzen et al. 2012) that actors use to influence socio-technical 
systems' change in what J.B Quinn (1978) would have called a 'logical incrementalism for muddling through'.

In this chapter, we attempt to shed light on the creation and ordering of boundary-work that are specific to certain regimes of action. These regimes invest in creating the materiality of a socio-technical imaginary and do not operate in a divide between niche and regime. Instead they construct a thick space of intermediary activities between various fields of practices (Gherardi and Nicolini 2006). Therefore, we draw upon recent approaches of intermediation in trans-organizational settings (Howells 2006; Klerkx and Leeuwis 2009; Manning and von Hagen 2010; Moss 2009; Steyaert et al. 2014) and more classical boundary-objects or boundary-organization approaches (Guston 2001; Star and Griesemer 1989; Vinck and Jeantet 1995) to explore how actors are trying to instigate a transition from current agri-food system practices to more sustainable ones through the creation of institutional settings of governance that rely upon the creation and the management of standardization processes. We argue that standard-setting activities provide spaces for boundary work where intermediaries must negotiate the knowledge and values of their own organizations in a 'pre-competitive' fashion, but also intervene in shaping the emerging governance structure. The result of this production of actionable knowledge is a standard, a boundary object, which enables actors to put their vision of sustainability into the prescription of practices for others based on a theory of their own practices. Within such a frame, the core question to be tackled in this chapter is thus: how is this process of intermediation stabilizing discourse internally and coordinating actors externally so to govern a transition to sustainability?

We attempt to provide a grounded answer to this question by a sociological examination of the development of the ISEAL Alliance's Assurance Code. The first author collected data between 2010 and 2012 through participant observation and informal interviews in the Technical and Steering Committees of the Assurance Code. These meetings were conducted according to the Chatham House Rule and therefore quotations are used from documents produced during the code development process. The author's notes taken during the meetings were handed over to ISEAL, who edited and published them as the public record. These public notes are used for quotations in the text. This methodological strategy was supported by ongoing reflexive discussions in a dedicated working group that served to enable 'counter-transference' and to detach the participant observer from the research context (Giami 2001). This method allows us to reflect upon the usefulness of this approach in understanding how actors construct the tools that enable them to influence the broader transition to sustainability.

Based on this case study, we put forward two main arguments. First, we propose that in order to understand transitions in progress, we should be attentive of how these processes are accompanied by intermediate actors (i.e., boundary-spanners, brokers, advisors, etc.). Second, we argue that intermediate objects (or boundary objects) are important in intermediation as they help actors to create actionable knowledge. These intermediation activities and the production of actionable knowledge are important to how actors can govern markets in the transition towards sustainable agriculture. 


\section{Transitions and standards in the making}

Batie (2008) argues that in order to address the 'wicked problem' of sustainability, there is a need for boundary organizations. We add there is also a need to better understand boundary organizations that broker the relationship between knowledge and action by co-producing knowledge and boundary objects (e.g., Guston 2001; Star and Griesemer 1989).

We situate our work specifically within this trend of studies in order to avoid the transactionalist theories of intermediaries as service go-betweens and knowledge transferors in a given industry (Howells 2006; Kirkels and Duysters 2010). As an analytical technique, we follow the notion of intermediaries put forward by Callon $(1986 ; 1991)$ in his sociology of translation to examine the innovation process and the design of socio-technical norms (Callon and Rip 1991). In this light we see intermediation as a set of dedicated activities that enable this passage and have the following properties: context-oriented, performative and reflexive (Steyaert et al., 2014). Therefore, intermediation activities are at the same time the means to accompany standardization and the goals to achieve through standardization (Callon 1991). Within the context of sustainability transitions, we envision the concept of intermediaries and intermediation in three ways, bearing in mind their functional performativity (Callon 2010).

Firstly, it spurs a conceptualization of standards as socio-technical and performative non-human intermediaries, which move and change while also facilitating movement in-between organizations and change in different socio-technical spaces (cf. Galland et al. 2012). In this case, they provide both a common communicational space and a common socialization process - or hybrid forum - for negotiation among stakeholders. Thus by examining standards as intermediaries we can explore how codified knowledge and discourses of intermediation activities are transferred between actors and how this process contributes to the socio-technical construction of a stable network.

Secondly, "actors are intermediaries that put other intermediaries into circulation" (Callon 1991, p. 141). Within innovation studies, these types of actors have been referred to alternatively as: change agents, linking agents, champions, facilitators, opinion leaders, third-parties, and brokers (Howells 2006; Klerkx and Leeuwis 2009; Thompson, Estabrooks and Degner 2006). Within political and organizational sociology, similar intermediaries are referred to as institutional, policy or ideational entrepreneurs (Garud, Jain and Kumaraswamy 2002; Kohler-Koch 2002). The role of these human intermediaries is described as managing the movement and transfer of knowledge (and innovations) between producers and users of knowledge. In hybrid forums, the boundary between these categories of producers and users of knowledge is not clear-cut. Thus, in this aspect of intermediation we seek to understand how actors align and coordinate the relationships between other actors in the network and interpret and stabilize the circulating standards and discourse.

Finally, we are interested in the reflexive process of doing intermediation. Callon (1991) argues that the "social can be read in the inscriptions that mark the intermediaries" (p. 140). So how can we go about reading these inscriptions as they are being made and grounded in the reflexive - perhaps strategicconsciousness of human actors? The first consequence of this statement is that intermediation activities have agency and structure in relation to the politics of forward-looking visions guided by a type of 
'knowing in action', which assumes a reflexive stance. Our social studies of intermediation must bear this in mind. The second consequence is obvious, but needs to be reasserted. The only way to observe convergence and irreversibilities that are important to the stabilization of networks and thus to the movement of sustainability transitions, is to be part of the process (Rolfsen et al., 2007), relying on the action-research tradition, newly renamed as participatory-research. In these instances, intermediation would be a reflexive process where researchers and practitioners co-evolve, generating reciprocal learning that likewise transforms the knowledge they produce and mobilize the forms of engagement established between them (e.g., Latour 1987; Steyaert 2009). It is in this sense that intermediation can be defined as a process of accompanying complex socio-technical transitions, where the ends and means of action are developed iteratively through social, discursive, and technological interactions. Thus, by linking discourse and practice through participant observation, we attempt to capture the dynamics and learning processes involved in intermediation.

\section{Intermediation within the ISEAL Alliance: Identifying matters of concern}

The ISEAL Alliance offers a framework for social and environmental standards schemes to work together to consolidate standard-setting and objective assessment. On its website, ISEAL traces its foundation to a meeting in the late 1990s of four certification organizations: Fairtrade Labelling Organizations International (FLO), Forest Stewardship Council (FSC), International Federation of Organic Agriculture Movements (IFOAM) and Marine Stewardship Council (MSC). During this meeting the benefits of sustained collaboration were debated and participants "were quick to recognize the high level of overlap in their systems and in 1999 signed an Agreement in Principle which led to them meeting regularly to learn about each other's programs and to find ways to collaborate". ${ }^{1}$ ISEAL was registered in the UK as a not-for-profit company in 2002 supported by six SDOs and one accreditation body (AB): FLO, FSC, IFOAM, International Organic Accreditation Service (IOAS), Marine Aquarium Council (MAC), MSC, Rainforest Alliance, and Social Accountability International (SAI). In 2013, there were fourteen full members, seven associate members, and fifty-six subscribers.

As ISEAL claims, their mission of defining, distinguishing, promoting and educating stakeholders about which standards are credible is their pathway for transitioning toward their vision of sustainability. Indeed, their video series launched in 2013 explains that 'standards show the way to sustainability'. Thus, part of this exercise requires the identification and resolution of certain matters of concern, particularly related to how these standards systems are attempting to re-organize the governance of agri-food systems. This is thus the core activity of creating a code for credible assurance and is a core component of intermediation.

The preliminary scoping exercises completed by ISEAL in 2011 found that the top four challenges to credible assurance were: Auditor competence, Resource constraints (cost, availability of auditors, others), Certification body ( $C B$ ) and $A B$ governance (or internal management), and Transparency of information about certification decisions. ${ }^{2}$ These responses were the initial identification of matters of

1 ISEAL Alliance (2012) 'About Us', < http://www.isealalliance.org/about-us/our-history > (accessed 13 November 2013).

${ }^{2}$ ISEAL Alliance. (2011) Assurance Code Critical Issues Survey Summary. 
concern and were brought into ISEAL discussions from individual member organizations. They reflect experiences 'out in the world' of trying to audit and certify farmers and firms for compliance with sustainability standards. These core concerns were codified into the second public draft of the assurance code in the following ways (see Box 1 ).

Box 1

Encoding the Auditor.

Framing Transparency.

Rationalization of Costs and Availability of Auditors.

Governing certification with ISO.

The purpose of rationalizing costs and availability of auditing activities led to mobilizing field-testing activities in March 2012. The ex-post analysis of the field-testing activity enables us to see how the matters of concern were further refined or abandoned as an issue of concern due to their sufficient codification within the standard. By using the template provided by ISEAL, the field testers assigned a value of worth to each requirement (mark from 1 to 10 , with 10 being the most valuable). The value represented ways to achieve credible assurance. In some cases this valuation project demanded almost as much discussion as the criteria itself.

Those areas of concern that were ranked, on average, greater than 8 on the 10 point scale were then prioritized as a result of the outcomes of field-testing. The top five were: Auditor Calibration, Witness Audits, Decision-Making Mechanism, Defining Auditor Requirements, and Sanctions. These five are technical specifications that can control auditor competence and oversight. 'Governing by numbers' (Porter 1995) was the preferred way to standardize the valuation of the underlying and diverse realities of farmers and firms.

In the May 2012 Newsletter, ISEAL re-summarized the matters of concern. There is a clear shift from costs and competence to oversight issues. Indeed, oversight became the core issue of concern in the joint technical and steering committee meeting in June 2012. In the email diffusion of the meeting agenda, the code coordinator highlighted some core issues that needed to be discussed. The recurring issues over the relationship between the ISEAL Code and the ISO codes was the top priority and the question of oversight and the nature of the different models of assurance were also mentioned. The ISO concern is based on the positioning of ISEAL as a mediator between members and ISO. On the one hand, ISEAL members are frustrated with the rigidity of ISO standards for conformity assessment and want to open their schemes to alternative ways to demonstrate compliance. But on the other hand, they still believe in the superiority of the ISO third-party certification and oversight model as the most credible way to ensure conformity. This dilemma posed a question about the role of ISEAL as an Intermediary and whose activities it should be intermediating. Some members felt that ISEAL was becoming a compliance organization, in a sense replacing ISO, rather than a 'platform for collaboration'. A synthetic account of the debate is presented in the Box 2 noting that these points were introduced with the following 
disclaimer: "There are a few broad issues that we would like to discuss. I would like you to consider these issues with the understanding that we will not be able to reach a conclusion on any of them - hence discussion will need to be time-limited."

Box 2

The relevant part goes to whether codes are compliance tools or learning tools. [They] either position themselves as a strong alternative to ISO, or they are learning tools that can help members.

New initiatives can't meet these in 5 years. If it is a compliance tool, are we creating a bar that is too high? But is it missing the point. The point is that we have a landscape of standards, and if you have really high bars then progress goes more slowly.

Indeed, there was no consensus reached on these issues in the discussion. Instead a holding pattern was introduced where the code would continue to be developed based on the technical recommendations of the committees and would be presented to the ISEAL Board for approval with a contingency plan for alternative specifications based on the outcome of the ISO problem. In the final code, ISEAL retained their requirement of ISO compliance, but suggested that there are other 'credible' ways to ensure compliance.

In this section we described how matters of concern take form, are debated and modified through processes and in the realm of practicing intermediation. In this case, what began with a concern about costs and competence became a debate about the fundamental role of ISEAL within the existing regime of conformity assessment. But have these matters of concern accompanied matters of facts?

\section{Making knowledge actionable: Experiencing the field test}

One of the core criteria of ISEAL's standards-setting code, is all standards - including ISEAL's own standards - be "expressed in terms of process, management and performance criteria, rather than design or descriptive characteristics" (ISEAL Alliance 2010). The guidance explains that standards must be written in a way that makes the intent of the standard clear and the criteria actionable. The preference for performance criteria is clear as these requirements focus on the outcomes of actual practice. The idea that ISEAL members facilitate the production of actionable knowledge in a move towards sustainability was also present during the public consultation on the assurance code. One stakeholder wrote that "An assurance code should include the requirement that any scheme which does not address primarily performance, is mostly useless, and undermines the credibility not only of the particular scheme, but of sustainability efforts in general" (ISEAL Alliance 2012). The process of making knowledge actionable for 'sustainability efforts' is through its co-production (cf. Jasanoff 2004) in an iterative process of interaction among stakeholders. Exploring this process requires a description of the ways in which the matters of concern identified above are co-evolving with their elaboration within the code. Through this description we capture the micro-politics of intermediaries.

\section{Figure 1: ISEAL Assurance Code Stakeholders}




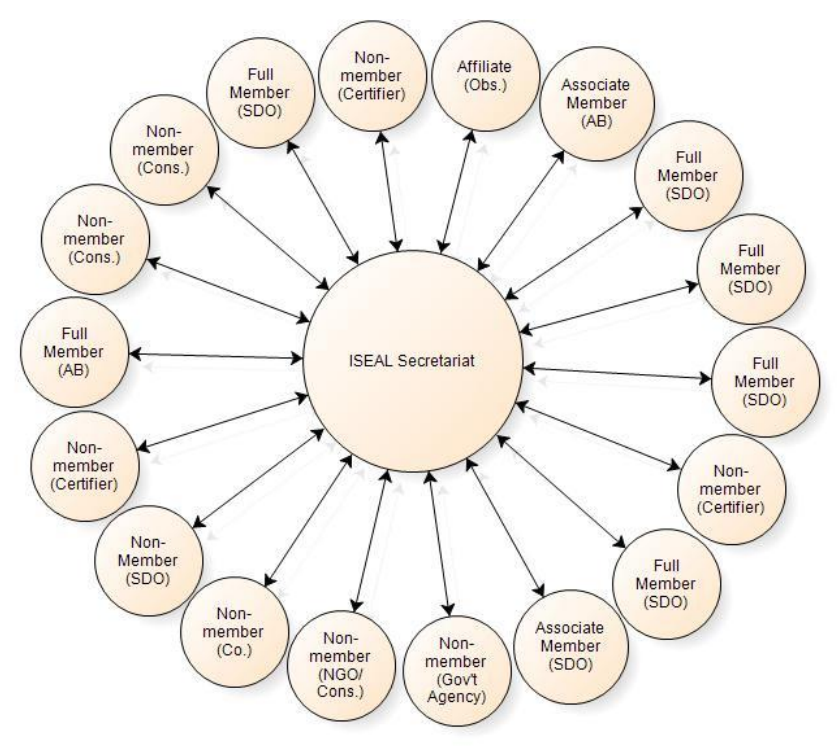

In the development of this code there was strong leadership from the secretariat, where most of the writing of the standard was done by ISEAL staff assigned to the code development. It is important to note that it is ISEAL policy to raise external donor funds that pay for the development of its standards. The Assurance Code was funded by the Packard Foundation and the Walton Foundation. The content, terminology and broader goals of the standard are debated within technical and steering committees, which were created through a nomination process by members and selected by the secretariat. Figure 1 illustrates the composition of the technical and steering committees for the Assurance Code. The composition of these committees represents the ISEAL requirement of balanced interests in that there is a good mix of the three different categories of membership (full, associate and affiliate) and nonmembers, as well as different types of organizations representing the public, private and NGO sectors. The enactment of who should be representing the different members and other stakeholders is based a notion of technical expertise. In other words, only the most experienced members (i.e., the original members of ISEAL) sent their senior standards-setting, certification, accreditation or management staff to participate in the code. The external participants are managers or consultants who have worked closely with ISEAL and its members over the years and bring a practical knowledge of conducting audits or advising firms or scheme owners how to conduct and improve audits.

The field test was commissioned by the ISEAL secretariat, completed by ten full members, one associate member and one affiliate, and the results were considered to be a very successful way to produce tangible outcomes in the standards-development process ("Field testing - it rocked! - we gave them money and they did it really well!"). What this comment refers to is the way in which the field testing exercise produced knowledge about the content of the standard that was easily understood by the ISEAL team and clearly identified those points that needed to be debated further and those points of contention that had been resolved. 
The timing of the field testing was also considered to be important to how 'actionable' knowledge was produced. In response to the researcher's provocative intervention that "perhaps the field testing should have occurred earlier in the code development process so to anticipate learning", two steering committee members responded negatively to this comment by justifying the importance placed on the role of experts and the idea that technical work must be done before scenarios can be implemented.

The ways in which the field tests themselves were organized can be identified as another important aspect of how 'actionable' knowledge was co-produced. ISEAL launched the field testing with the following objective: "The objective of field testing the draft Assurance Code is to investigate its feasibility; thereby to make it a better and more useful Code." ${ }^{3}$ ISEAL explicitly requested a desk review of the code and provided a template to assist in the activity. In addition to completing the template (described in the last section), the field testers were to respond to the questions detailed in Box 3.

\section{Box 3}

1. How your assurance rates against the proposed requirements, e.g.: equivalent, not applicable, more stringent, less stringent

2. Does the requirement help to improve the quality of assurance? If not, why not?

3. Is the requirement feasible? If not, what would make it more feasible?

4. What are the constraints (if any) to meeting this requirement?

These questions required reflection and intermediation on the part of the field testers as they needed to enroll knowledge of the assurance code, knowledge of their own standards, knowledge of the matters of concern in the implementation of their standard and knowledge related to broader technical concepts such as risk assessment, sampling, auditor competency and apply these in the review. In the three observed field tests, each actor enrolled different knowledge and intermediaries into their respective activities. These co-produced different ways of knowing and doing assurance. It is interesting to note that the third field test was the only test where the researcher participated for the duration of the test. The other two tests were truly interpreted as desk reviews (with computers) and the participation by the researcher was a reflexive interviewing exercise at one point during the process, rather than a complete observation.

The first field test was undertaken by an $A B$. Those who conducted the field test were a staff member and a consultant from a SDO that uses the $A B$ to accredit their certifiers. At the time of the field test, this staff member had participated in neither the technical nor steering committee. The discussion regarding the field testing activity was very internally focused, partly because of the lack of awareness of the matters of concern discussed at the committee level, and partly because of concerns over jurisdiction between international accreditation and national accreditation for the right to 'accredit' for ISO 17065. Given the construction of the international accreditation model according to ISO 17011 standards, this $A B$ considered that their system was more stringent or equivalent to the ISEAL code Model $A$ (third-party

\footnotetext{
${ }^{3}$ Assurance Code Field Testing Terms of Reference, April 2, 2012.
} 
assurance) on all applicable requirements. Indeed, discussions of ISO standards dominated the discussions and the report submitted to ISEAL.

The second field test was undertaken by a CB. A single staff member, belonging to the steering committee, conducted the desk review and spoke with the appropriate colleagues about relevant issues. In discussions one focus was on the relationship between the ISEAL Assurance Code and the ISO standards. The comment made was that "the guidance that is specific to the implementation of social and environmental standards systems and that is not sufficiently addressed in ISO norms is not made very explicit". The model of assurance of the certifier's standard scheme was also debated. Overall, this CB found their standards system less stringent than the ISEAL Code on 11 of the 16 applicable requirements.

The third field test was conducted by a SDO between a staff member who is part of the technical committee, a staff member who is not, and a consultant from a CB. This SDO used the exercise to diagnose the status quo of their system vis-a-vis the ISEAL code, as well as providing comments to improve the draft during the second public consultation. Thus, this was seen not only as a check-box exercise on whether or not their system was up to code, but also as a way to feed their practical experience back into the code development process. Current problems that their clients had with their standard were reflected upon. Solutions were either an adjustment to the SDO's standard or an adjustment in the ISEAL standard. ISO standards were also debated by the group and the requirement that ISO 17065 or 17021 , etc. standards must be 'substantially fulfilled' was discussed at length. What was to be required in practice according to this requirement was not clear in the code and this collective sought clarification, as long as this kept the requirement flexible enough so that the SDO would be able to comply with it (i.e., not meaning obligatory accreditation).

These three ways of conducting tests reflect the micro-politics of the co-production of knowledge by their approaches. First, the ISEAL commission of a 'desk review' was interpreted differently in each case by the decisions over which, and how, different actors and intermediaries should be enrolled. Secondly, those areas that were highlighted as matters of concern reflect the internal politics of each organization as this exercise was meant to be used as a way to determine whether each organization would face difficulties complying with the ISEAL standard. Moreover, there was a difference observed in the focus on concerns internal to member organizations versus broader ISEAL community concerns over creating systems that will effectively transition to sustainability. Those who had been more active in the ISEAL committees were able to locate their concerns more readily within the broader debates, while those who were not necessarily focused on their own experiences. Finally, these micro-politics of testing were constrained by the template provided by ISEAL and thus while they were debated at length in the field tests; they disappeared in the translation and alignment of heterogeneous practices into the template. However, each group did make note of their most pressing concerns, particularly regarding oversight issues, in the narrative reports that explained their template results. These concerns related again to how they saw the ISEAL process as bounding actionable knowledge.

As this section illustrates the mobilization of primarily experiential knowledge has been paramount to the 'success' of the field testing exercise. Also, the ability to preemptively evaluate the 'goodness of fit' 
of the assurance code to each individual standard ensured the production of actionable knowledge that will contribute to the proposed transition to sustainability. What this section also showed is how the coproduction of knowledge within the field tests fed on and contributed to larger debates within ISEAL and smaller debates within the organizations themselves. This fluidity illustrates how the boundaries of the knowledge co-produced through this exercise are interdependent on the materiality of the intermediaries enrolled and the role of experts in influencing the standards-setting process in the interests of their own organizations.

\section{The role of reflexivity}

Reflexivity and social learning have been heralded as important aspects of modernization (Beck, Giddens and Lash 1994). One of the empirical questions of intermediation can be posed as the following. Is intermediation a reflexive activity and where can we locate the inscriptions that mark the intermediaries?

While representatives from the donors were not present in the code development process, and ISEAL staff claim that their influence is minimal in ISEAL affairs, the monitoring and evaluation framework used by Packard Foundation has a strong focus on reflexivity and shapes how the ISEAL staff must think about the outcomes of their work. The 'Linking Knowledge with Action' framework was developed based on the framework for global environmental assessments developed by a team of STS researchers. ${ }^{4}$ ISEAL thus must report back to Packard on the following categories of questions: Ripe Situation, Spanning Boundary, Capacity, Joint Production, Behavioral Change, and Influence. This framework was adapted to the ISEAL Assurance Code context. An illustrative question regarding what is meant by capacity is the following: "How are the technical committees addressing knowledge gaps, contradictory information, or inadequate data in the Code development process?" ${ }^{5}$

The need to be able to answer questions like the above contributed to the reflexive way in which ISEAL managed meetings and communication about the Assurance Code, which is where we can see the first inscriptions. Throughout the code development process, and after, ISEAL released a monthly Assurance Code newsletter that kept the broader interested public informed about what was going on inside the standards-setting process (Box 4)

\section{Box 4}

The committee members reviewed the new draft and provided in-depth prospective and suggestions for improvement. It was an intense and productive meeting as indicated by Allison Loconto, our Assurance Code process researcher at INRA-SenS:

"My reading of the group atmosphere is that they were really aware of the consequences of some of these decisions that they were taking and were more inclined to speak up than during the other

\footnotetext{
${ }^{4}$ Interview with ISEAL staff member on March 4, 2011. See: Mitchell, R.B., W.C. Clark, D.W. Cash, and N.M. Dickson (eds) (2006) Global Environmental Assessments: Information And Influence (Cambridge, MA: MIT Press).

${ }^{5}$ ISEAL Alliance. Assurance Code - Linking Knowledge with Action. March 3, 2011.
} 
meetings. Also, I really do think that the field testing was a great exercise because as you can see in the notes, there was much more reflection in this meeting about how certain elements fit or don't fit with the specific schemes. My impression is that this exercise brought the code from the abstract into a tangible reality for the members." 6

In this example, the traces of the researcher as an intermediary are clear. First, the researcher was the dedicated note-taker in all of the meetings. The notes were typed as verbatim as possible during the meetings. These notes were shared immediately following the meetings with the two ISEAL staff members. The Code coordinator took the raw notes and consolidated them into a shorter summary, which was approved by the Code director before being disseminated to the committee members and being published on the website. Thus in this sense, the researcher's vision of the event was taken as the basis for constructing the collective's account of the event.

Second, the researcher was relied upon as an expert in social science methods, particularly related to sampling and risk assessment. There was a general lack of technical knowledge in the collective about these two issues, which were supposed to be highlighted in the code as ways to increase rigor while reducing certification costs. The sections on sampling and risk went through a number of iterations and discussions throughout the life of the code development. Risk assessment passed from a tool to be employed, to an overarching framework for determining how to structure a standards system, down to the requirement of a risk management plan and guidance for risk-based sampling. Sampling was a particularly difficult section to 'get right' in the discussions and the researcher was specifically requested to contribute. ${ }^{7}$

This intermediation exercise therefore was quite unique in that there were two mechanisms built into it that encouraged reflexivity: the donor-induced reflexive management and the researcher as a participant observer. This reflexivity was evident through the shifting roles of the other 'experts' throughout the process. While the ISEAL staff shifted between administrators and experts, the others negotiated their roles as experts and their roles as representatives of their own organizations. At the January 2012 meeting, about halfway through the intermediation process, the experts experienced a shift in how they saw their roles. While they entered into the discussions as experts looking for the 'best' solutions to their concerns, at this point the reality kicked in of needing to represent the interests of their own organizations that have 'less than perfect' standards. This was even more apparent following the field test, as the debates moved from more of an academic debate over the best tool for assurance to the landscape pressures from the ISO system. One participant explained the problem, "how would you design a standard? But in the real world, if you haven't done this [field testing] as an exercise, then you won't learn." This shift is significant in showing the dynamic interactions between micro-political concerns and the landscape pressures in sustainability transitions. The concern about the ISO standards remained dominant until the launch of the code because of a pressing legal dispute over the EU's interpretation of who can conduct accreditation. This highlights the important situatedness of intermediation and its role in transitions. In order for ISEAL to effectively transition its vision of

\footnotetext{
${ }^{6}$ Assurance Code Newsletter, June 2012.

${ }^{7}$ Email from technical committee member, July 19,2012.
} 
sustainability it must be able to reflexively manage these multiple roles and landscape concerns as it encodes them into its tools for transition.

\section{Conclusions}

Within agri-food systems, scholars have focused on the emergence of novelties as 'seeds of transitions' (Wiskerke and Van der Ploeg 2004). These are ideas, techniques and practices that modify or break with the existing norms of the dominant socio-technical agri-food system. These can be found in situated research activities, field practices or value chains that are guided by sustainability goals (Barbier 2008). Brunori et al. (2011) argue that alternative agri-food networks (AAFNs) are examples of niches, as they have stabilized beyond novelties through the creation of organizing visions and alternative technoeconomic networks of food production, consumption and distribution. These are contingent relational activities where actors within AAFNs are interdependent on social actors within and outside the niche they are carving (Lamine 2011). Many AAFNs have adopted standards as a fundamental technology around which they organize diverse actors in a common socio-technical imaginary of sustainability. This is part of the standardization trend that has been noted in global transformations of the rural.

In our reflection about sustainability transitions explored through the above case study, we dealt with the concept of intermediaries and intermediation in order to account for the performativity of this imaginary, and how it is practiced. We described the role of intermediaries in the ISEAL Assurance Code as a process of coordination between donors and members that enrolls technical experts internal and external to its membership in the development of an intermediary object (the standard). This standard has been used as the material tool to organize discourse and actors in the sustainability movement. This case illustrates the following broader points about intermediation.

First, the standard that is being created is itself acting as an intermediary as it moves between actors and becomes performative. This performativity refers to the way in which the standard as a document travels and must be interpreted by those that attempt to use or apply it. In this case, it served to facilitate the transmission of the knowledge (and values that were negotiated during the production of the artefact) into action. Thus, the standard is truly an actant in the way envisaged by Latour (1987).

The second understanding of intermediation focuses on how these exercises in standards-setting are part of a longer-term process of transitioning innovative approaches to sustainable agriculture. As shown by the micro-politics of certification, we must go deeper in the study of standardization processes in order to avoid a far too simplistic view of sustainability as a journey from niches ascribed in a regime of certified sustainability, established in the landscape of agricultural production and consumption. In this case we see standards mobilized as market mediation strategies (Dubuisson-Quellier, 2013) of intermediaries (SDOs) who stabilize discourse and coordinate actors. In this particular case, we examined the knowledge regimes that are invoked in the processes of intermediation and reflected upon how these fed into the management of a transition.

Finally, the ability to observe intermediation, through participatory research, allows us to make sense of the exchanges and feedback loops between groups that is difficult to achieve with historical methods or even interviews or focus groups. Reflexivity and social learning are considered to be core parts of both 
transition management and intermediation. They are also promoted as 'best practice' in the recent calls for public sociology (e.g., Burawoy 2005).

What this case thus illustrates is the dynamic nature in which the activities of intermediation at a regime level feed on and are fed by activities and knowledge that enter into both discourse and practice from landscape pressures and niche innovations. We therefore argue that by paying attention to these microdynamics of intermediation we can better capture the dynamics of sustainability transitions in the making. Transition management emerged as an approach that attempts to resolve questions related to the governance of large-scale societal transformations (e.g., Schot and Geels 2008; Smith, Stirling and Berkhout 2005). Strategic niche management (Schot and Geels, 2008) is a way to understand how this diversity is managed. Yet transition management is also criticized for glossing over politics, controversy and the practicalities of everyday practices that are necessarily part of the practice of managing transitions (Shove and Walker 2007). The recent work on sustainability transitions note these shortcomings and propose that new research be conducted that can bridge these gaps (Grin, Rotmans and Schot 2010).

Here we suggest that focusing on how intermediaries accompany change can reveal the controversies, bring the politics into studies of transition management, and help to identify opportunities to influence change. The construction of actionable knowledge is an important act of intermediation as the politics of knowledge are tamed through standardization. In this sense, we see a role for the activities of intermediation in socio-technical transitions where we envision classical intermediation as a process of 'accompanying and brokering change', but also as a process of socializing the wicked nature of the problems. Put differently, we believe that reflexivity in intermediation activities is enabling actors to consider changes as do-able activities outside the rationalization of their daily practices under the landscape pressure of achieving clearly delineated goals though specified means (in this case through standards). Within sustainability transitions, the definition of goals relies upon a critique of the present while the definition of the means of how to get there becomes a professional activity of making knowledge actionable (cf. Barbier and Lemery 2000). 
Amin, Ash, and Joanne Roberts. 2008. "Knowing in action: Beyond communities of practice." Research Policy 37(2):353-69.

Argyris, C, 1995. "Action science and organizational learning." Journal of Managerial Psychology 10(6):20-26.

Barbier, Marc. 2008. "Bottling water, greening farmers: the socio-technical and managerial construction of a 'dispositif' for underground water quality protection." International Journal of Agricultural Resources, Governance and Ecology 7(1):174-97.

Barbier, Marc, and B Lemery (Eds.). 2000. Learning through processes of change in agriculture: $a$ methodological framework. Paris: INRA-Springer.

Batie, Sandra S. 2008. "Wicked Problems and Applied Economics." American Journal of Agricultural Economics 90(5):1176-91.

Beck, Ulrich, Anthony Giddens, and Scott Lash. 1994. Reflexive modernization: politics, tradition and aesthetics in the modern social order. Cambridge: Polity Press.

Brunori, Gianluca, Adanella Rossi, and Vanessa Malandrin. 2011. "Co-producing Transition: Innovation Processes in Farms Adhering to Solidarity-based Purchase Groups (GAS) in Tuscany, Italy." International Journal of Sociology of Agriculture and Food 18(1):28-53.

Burawoy, Michael. 2005. "2004 ASA Presidential Address: For Public Sociology." American Sociological Review 70(1):4-28.

Callon, Michel. 1986. "Some elements of a sociology of translation: domestication of the scallops and the fishermen of St Brieuc Bay." Pp. 196-233 in Power, Action and Belief. A New Sociology of Knowledge?, edited by J. Law. London: Routledge \& Kegan Paul.

Callon, Michel. 1991. "Techno-economic networks and irreversibility." Pp. 132-63 in A Sociology of Monsters: essays on power, technology and domination, edited by J. Law. London: Routledge.

Callon, Michel. 2010. "Performativity, Misfires and Politics." Journal of Cultural Economy 3(2):163-69.

Callon, Michel, and Arie Rip. 1991. "Forums hybrides et négociations des normes sociotechniques dans le domaine de l'environnement. La fin des experts et l'irrésistible ascension de l'expertise." Environnement, Science et Politique, Cahiers du GERMES 13:227-38.

Dubuisson-Quellier S. 2013. A market mediation strategy: how social movements seek to change firms' practices by promoting new principles of product valuation, Organization Studies 34(5-6):683703

Elzen, Boelie, Marc Barbier, Marianne Cerf, and John Grin. 2012. "Stimulating transitions towards sustainable farming systems." in Farming System Research, edited by I Darnhofer and Dedieu Benoit. Montpellier: Editions QUAE.

Galland, Jean-Pierre, Aurelie Delemarle, Allison Loconto, and David Demortain. 2012. "Coping with standard diversity: An analytical framework - the standard life cycle." in 28th EGOS Colloquium. Aalto University \& Hanken School of Economics, Helsinki, Finland

Garud, Raghu, Sanjay Jain, and Arun Kumaraswamy. 2002. "Institutional Entrepreneurship in the Sponsorship of Common Technological Standards: The Case of Sun Microsystems and JAVA." Academy of Management Journal 45(1):196-214.

Gherardi, Silvia, and Davide Nicolini. 2006. Organizational Knowledge: The Texture of Workplace Learning: Wiley.

Giami, Alain. 2001. "Counter-Transference in Social Research: George Devereux and Beyond." in Papers in Social Research Methods Qualitative Series no 7 London: London School of Economics and Political Science Methodology Institute 
Grin, John, Jan Rotmans, and J. W. Schot. 2010. Transitions to sustainable development : new directions in the study of long term transformative change. New York: Routledge.

Guston, D. H. 2001. "Boundary organizations in environmental policy and science: an introduction." Science, Technology, and Human Values 26(4):399-408.

Hatanaka, Maki, Jason Konefal, and Douglas Constance. 2012. "A tripartite standards regime analysis of the contested development of a sustainable agriculture standard." Agriculture and Human Values 29(1):65-78.

Howells, Jeremy. 2006. "Intermediation and the role of intermediaries in innovation." Research Policy 35(5):715-28.

ISEAL Alliance. 2010. "Setting Social and Environmental Standards v5.0: ISEAL Code of Good Practice." London: ISEAL Alliance.

ISEAL Alliance. 2012. "Assurance Code Comments - First Consultation Nov 12011 - Dec 31 2011." London: ISEAL Alliance.

Jasanoff, Sheila (Ed.). 2004. States of knowledge: the co-production of science and social order. London and New York: Routledge.

Jasanoff, Sheila, and Sang-Hyun Kim. 2009. "Containing the Atom: Sociotechnical Imaginaries and Nuclear Power in the United States and South Korea." Minerva 47(2):119-46.

Jørgensen, Ulrik. 2012. "Mapping and navigating transitions-The multi-level perspective compared with arenas of development." Research Policy 41(6):996-1010.

Kirkels, Yvonne, and Geert Duysters. 2010. "Brokerage in SME networks." Research Policy 39(3):375-85.

Klerkx, Laurens, and Cees Leeuwis. 2009. "Establishment and embedding of innovation brokers at different innovation system levels: Insights from the Dutch agricultural sector." Technological Forecasting and Social Change 76(6):849-60.

Kohler-Koch, Beate. 2002. "On Networks, Travelling Ideas, and Behavioural Inertia." Pp. 87-103 in Regionales Europa - Europäisierte Regionen, edited by Thomas Conzelmann and Michèle Knodt. Frankfurt/Main, Germany: Campus Verlag GmbH.

Lamine, Claire. 2011. "Transition pathways towards a robust ecologization of agriculture and the need for system redesign. Cases from organic farming and IPM." Journal of Rural Studies 27(2):209-19.

Latour, Bruno. 1987. Science in Action: How to Follow Scientists and Engineers through Society. Milton Keynes, England: Open University Press.

Levin, Kelly, Benjamin Cashore, Steven Bernstein, and Graeme Auld. 2012. "Overcoming the tragedy of super wicked problems: constraining our future selves to ameliorate global climate change." Policy Sciences 45(2):123-52.

Loconto, Allison, and Marc Barbier. 2012. "Transitioning a Sustainability Regime: Standards as Governing Devices." in The Governance of Innovation and Socio-Technical Systems: Theorising and Explaining Change. International Workshop. Copenhagen Business School, Denmark.

Loconto, Allison, and Lawrence Busch. 2010. "Standards, techno-economic networks, and playing fields: Performing the global market economy." Review of International Political Economy 17(3):507 36.

Loconto, Allison, and Eve Fouilleux. 2014. "Politics of Private Regulation: ISEAL and the shaping of transnational sustainability governance." Regulation \& Governance 8(2):166-85.

Manning, Stephan, and Oliver von Hagen. 2010. "Linking local experiments to global standards: How project networks promote global institution-building." Scandinavian Journal of Management 26(4):398-416.

Moss, T. 2009. "Intermediaries and the governance of sociotechnical networks in transition." Environment and Planning A 41(6):1480-95.

Mutersbaugh, Tad. 2005. "Just-in-space: Certified rural products, labor of quality, and regulatory spaces." Journal of Rural Studies 21:389-402. 
Porter, Theodore M. 1995. Trust in Numbers: The Pursuit of Objectivity in Science and Public Life. Princeton: Princeton University Press.

Quinn, James Brian. 1978. "Strategic Change: 'Logical Incrementalism'." Sloan Management Review Fall:7-21.

Rolfsen, M, Johnsen, A, and Knutstad G, 2007. "Action Engagement: Improving Researchers' Involvement in Action Research Projects." Syst Pract Act Res 20:53-63

Schot, Johan, and Frank W. Geels. 2008. "Strategic niche management and sustainable innovation journeys: theory, findings, research agenda, and policy." Technology Analysis \& Strategic Management 20(5):537-54.

Shove, E., and G. Walker. 2007. "CAUTION! Transitions ahead: politics, practice, and sustainable transition management." Environment and Planning A 39(4):763-70.

Smith, Adrian, Andy Stirling, and Frans Berkhout. 2005. "The governance of sustainable socio-technical transitions." Research Policy 34(10):1491-510.

Star, S. L., and J. R. Griesemer. 1989. "Institutional ecology, 'translations,' and boundary objects: Amateurs and professionals in Berkeley's Museum of Vertebrate Zoology, 1907-39." Social Studies of Science 19:387-420.

Steyaert, P. 2009. "Intervenir pour connaître et agir : le chercheur "acteur-auteur" du changement technique et social." in Dynamique des savoirs, dynamique des changements. Quelles pratiques de recherche pour quels développements ?, edited by Pascal Beguin and Marianne Cerf. Toulouse: Editions OCTARES.

Steyaert, P., Barbier, M., Cerf, M., Levain A., and Loconto A., 2014. "Role of intermediation in the management of complex socio-technical transitions", in Proceedings of the SISA International Workshop, edited by Boelie Elzen and Marc Barbier, Paris, June 2014.

Thompson, Genevieve N., Carole A. Estabrooks, and Lesley F. Degner. 2006. "Clarifying the concepts in knowledge transfer: a literature review." Journal of Advanced Nursing 53(6):691-701.

UNFSS. 2012. "Voluntary Sustainability Standards: Today's landscape of issues \& initiatives to achieve public policy objectives. Part 1: issues." Geneva: United Nations Forum on Sustainability Standards.

Vinck, Dominique, and Alain Jeantet. 1995. "Mediating and Commissioning Objects in the Sociotechnical Process of Product Design : a conceptual approach." Pp. 111-29 in Designs, Networks and Strategies, edited by Donald Maclean, Paolo Saviotti, and Dominique Vinck: Directorate General Science, R\&D.

Wiskerke, J.S.C., and J.D. Van der Ploeg. 2004. Seeds of Transition: Essays in Novelty Production, Niches and Regimes in Agriculture: Royal Van Gorcum. 